$\xi=1$ 圆

\title{
Smart Technological Learning Conceptual model
}

\author{
Cakula Sarma* \\ Vidzeme University of Applied Sciences, Riga Technical University \\ *Corresponding author E-mail: Sarma.cakula@va.lv
}

\begin{abstract}
Lifelong learning in one of most important aspects of nowdays educational system, which is understood as continuation of the previously acquired education and the enrichment of the professional skills according to the demands of the vocation in question. It is very important to figure out the most effective technological solutions and principal directions for implementing work-based learning strategies in the learning process. New smart learning individually oriented methodology has been developed based on human individual perception for fast growing information and big data society.
\end{abstract}

Keywords: Individualized and personalized learning; virtual information system; knowledge sharing; learner advisory system

\section{Introduction}

With the development of new technologies and the necessity to adapt to the new demands of the job market, the need for further education increases yearly. As such, the continuing learning and development of skills throughout their lifespan has become a cornerstone of the modern occurrence of lifelong learning $[1,2]$.

There are many policy documents exist that determine strategy of education development on both national as well as European level. The policy document that determines development of education development structure and perspectives for the upcoming seven years is the "Guidelines for Education development 2014 - 2020" [3]. The main purpose of those is to promote inclusive education for personal development, human well-being and sustainable advancement of the state.

The strategic framework of e-governance determined by "Guidelines for development of the information society 2014-2020" [3] describes crucial elements that need to be established and effectively developed to promote development of e-governance. The purpose of this document is to establish a knowledge-based economy and increase the general quality of life through providing access to technologies thus improving the overall quality of life, investing in development of effectiveness of public administration and national competitiveness, economic development and creating new jobs.

Main indicators for evaluation of the planning period of year 2014 -2020 are:

- the number of adults (25-64 years old) engaged in an adult educational program,

- the percentage of adults in all those involved in continued education/returning to formal education,

- the number of people who have gained their qualification outside the formal framework of education and had it equated to the national standard.

It is also has been recommended that the work on expanding opportunities of further education in regional universities continued, according to the requirements of regional development and de- mands of the labour market. Adults normally enjoy being actively involved in educational processes but currently this does not happen through collaborative means. For this, extra motivation needed, as well as easily comprehensible and engaging technological solutions, which encourage to collaborate and to learn from one another. There is a problem that existing learning models are too weak for student motivation and quick acquiring necessary knowledge and skills.

The goal of the paper is to find main principles of nowdays learning and to develop smart learning technological conceptual model in fast growing information and big data society. Paper includes theoretical analyses, conceptualization, using results of previous empirical researches, administrative documents and creative experience.

As the result of the paper new smart learning technological conceptual model has been developed.

\section{Main Focuses of Nowdays Learning in Fast Growing Information and Big Data Society}

\subsection{Analytic and Shared Cognition}

Nowdays paradigms in pedagogy:

- In the center of learning there is subject, what means that the didactic process develops from subject logic and very often contracted on comprehension of didactic rules, respecting programs demands of subject;

- pedagogical process focused on the teacher's activity, defining didactic goals, means, organization of work, teacher-pupil relations, teacher-leading position, which most often manifests itself as normative pedagogical process;

- the pedagogical process oriented to society needs targets, means and mutual relations for the public interest; the promotion of the development of a person is understood as its pursuit of the interests of society or of a dominant group as a value; 
- at the center of the learning process is a student with individual characteristics; teachers are guided by the perceptions of pupil opportunities;

- the pedagogical process oriented on the learner's activity, which is based on the understanding of the activity as a basis for the development of the personality, in which personality traits manifests itself and develops and whose quality is determined by the person's characteristics and needs of the subject [4].

The basic guiding principles of the developed D. Kolba model are $[5,6,7]$ : Learning is an ongoing process; it's not just the end result; learning is based on personal experience; learning involves the interaction between the individual and the environment, whereby experience is transformed into action and knowledge.

Cognition is the ability to process information though perception (stimuli that we receive through our different senses), knowledge acquired through experience, and our subjective characteristics that allow us to integrate all of this information to evaluate and interpret our world. In other words, cognition is the ability that we have to assimilate and process the information that we receive from different sources (perception, experience, beliefs...) to convert them into knowledge. Cognition includes different cognitive processes, like learning, attention, memory, language, reasoning, decision making, etc., which form part of our intellectual development and experience. Analytical method based on document analysis used in the production of controlled dictionaries [8].

Cognitive process could be analysed from six different aspects: perception, attention, memory, thought, language, learning. It is very difficult to improve cognition therefore there are different researches in this field $[9,10,11,12,13]$. Also scientists made a tool and strategy oriented to improve cognition and cognitive performance [14, 15].

\subsection{Individualized and Personalized Learning}

Individualized learning, or individualized instruction, is a method of teaching in which content, instructional technology, and pace of learning are based upon the abilities and interest of each learner. There are five steps to individualize learning:

1. set clear and specific goals;

2. make goals challenging and realistic;

3. make goals dynamic and review regularly;

4. let students to know their progress;

5. involve supporters (parents, friends e.t.c.) [16].

Instruction calibrated to meet the unique pace of various students is known as individualized learning. If differentiation is the "how," then individualization is the "when." The academic goals, in this case, remain the same for a group of students, but individual students can progress through the curriculum at different speeds, based on their own particular learning needs. This approach serves students who may need to review previously covered material, students who don't want to waste time covering information they've already mastered, or students who need to proceed through the curriculum more slowly or immerse themselves in a certain topic or principle to really get it.

Perhaps the most confusing term of them all is personalized learning. Some misuse the term, thinking it refers to a student's choice of how, what and where they learn according to their preferences. Others confuse is with individualization, taking it as a reference to lessons that are paced at different rates to accommodate different students.

There are different definitions overlaps in at least one key area with personalized learning;

- Adaptive learning: technology used to assign human or digital resources to learners based on their unique needs;

- Individualized learning: the pace of learning is adjusted to meet the needs of individual students;

- Differentiated learning: the approach to learning is adjusted to meet the needs of individual students;
- $\quad$ Competency-based learning: learners advance through a learning pathway based on their ability to demonstrate competency, including the application and creation of knowledge along with skills and dispositions [17].

Really, personalized learning refers to the whole enchilada: learning that is tailored to the preferences and interests of various learners, as well as instruction that is paced to a student's unique needs. Academic goals, curriculum and content - as well as method and pace - can all conceivably vary in a personalized learning environment.

Unlike individualized instruction, personalized learning involves the student in the creation of learning activities and relies more heavily on a student's personal interests and innate curiosity. Instead of education being something that happens to the learner, it is something that occurs as a result of what the student is doing, with the intent of creating engaged students who have truly learned how to learn. Human individual perception can be categorized as a type of nomothetic psychology and developed by socionic's theory.

There is a relatively new theory about personality types which was developed by a Lithuanian scientist Aushra Augusta in 1970's [18]. It is called Socionics and it is based on Jungian four personality types. While Jung mostly focussed on personality types as individuals. Based on Socionics, there are 16 types of personalities and respectively 16 types of possible perception of information. All of the people have their strengths and weaknesses and Socionics has defined what the strengths and weaknesses of each sociotype are [19, 20, 21, 22, 23].

Closely related to personalized learning, goals based on curriculum design and standards may be the same for all students, but the individual learning profile and plan for each student may vary. This is because each learner progresses through the material at different speeds, according to his or her own learning needs and abilities. For example, a student might take longer to progress through a given topic, skip topics that cover information already known, or repeat topics on which they need more help.

Providing truly differentiated and individualized instruction has been a goal of educators for decades, but new technologies available today are empowering schools to implement this form of education in a way never before possible.

Modern classrooms are teeming with students of varying interests, backgrounds, abilities and learning needs. To engage these students, learning must be every bit as diverse as they are. Peggy Grant tease out the crucial nuances that distinguish these terms in an attempt to demystify the approaches they refer to so that educators may better initiate more effective learning techniques [24].

\subsection{Reflective Learning}

Reflective learning is a way of allowing students to step back from their learning experience to help them develop critical thinking skills and improve on future performance by analysing their experience. Reflective learning involves students thinking about what they have read, done, or learned, relating the lesson at hand to their own lives and making meaning out of the material.

Reflection is indicative of deep learning, and where teaching and learning activities such as reflection are missing - only surface learning can result. Reflection has been described as a deliberate process during which the candidate take s time, within the course of their work, to focus on their performance and think carefully about the thinking that led to particular actions, what happened and what they are learning from the experience, in order to inform what they might do in the future $[25,26]$.

There are several advantages of reflective learning for the student, which include:

- Accepting responsibility for your learning and, as a result, for your personal growth

- Becoming metacognitive, or aware of your internal thinking processes

- Becoming aware of your motives with your actions 
- Seeing a link between the work you are putting into learning and what you are getting out of it.

\section{Smart Learning Environment Conceptual Model}

Based on all these aspects the smart learning environment provides students with adaptive and personalized learning and assessment, including through multi-modal/multi-sensory interaction technologies and advanced interfaces. Industry-led approach in cooperation with academic will lead to market oriented education.
The digital ecosystem for learning - including formal and informal learning, including workplace learning - will be developed using integrated tools and systems, personal characteristics for adaptive learning.

Future learning technologies have to be smart and effective:

Smart: high performance, personaly adaptive and motivated for learner. System have to be self development.

Effective: in short time, in easiest way to give the best result. Learner have to get higher level of knowledge, skills and competencies.

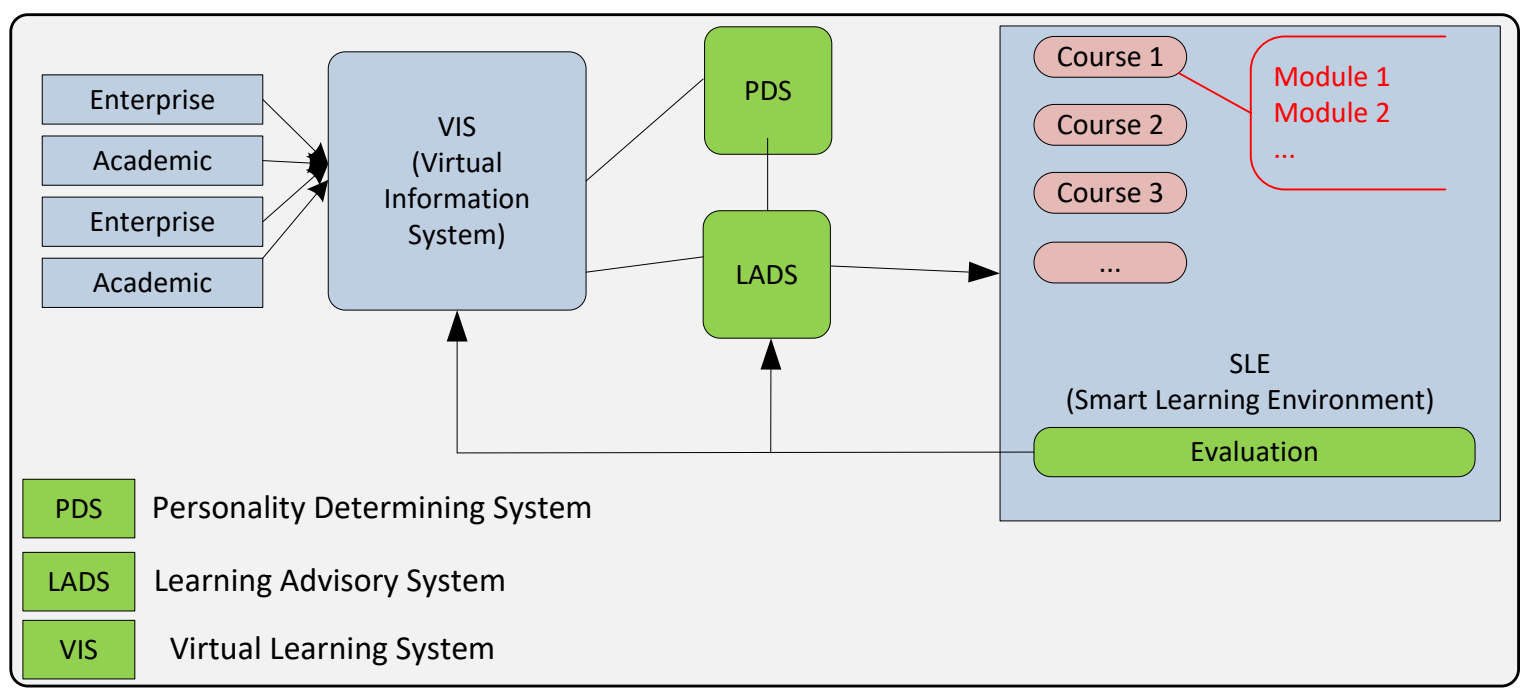

Fig. 1: Learning and Assessment system (LAS)

\subsection{Technological Model}

New learning individually oriented methodology should be developed based on human individual perception - how individuals select and process information, Neil Fleming's pedagogic theory, educational psychology and artificial intelligence for formal and informal education, including workplace learning. Human individual perception can be categorized as a type of nomothetic psychology and developed by socionic's theory. Basic concept of the learning and assessment system (LAS) is described in figure 1.

Knowledge management requires technologies to support the new strategies, processes, methods and techniques to better create, disseminate, share and apply best knowledge, any time and any place. It is a systematic process that focuses on the acquisition, transfer and use of effective, topical knowledge and best practice, thus promoting sustainable operation of an organization.

Knowledge sharing through participation and social interaction is an important facilitator of knowledge acquisition, and hence of learning. To enable successful knowledge flow, a virtual system must ensure services allowing entrepreneurs to learn everything they need at any given moment and share their experience in the most effective way if they are willing to do so. VIS is used as a tool to achieve the goal of converting tacit knowledge into explicit by maximizing learning opportunities and internalizing knowledge by experience in the workplace, online and classroom. The self - developmental adaptive and personalized learning and assessment system (LAS) is built on advances on neuroscience, pedagogical and learning theories, educational psychology as well as artificial intelligence including modal/multisensory technologies.

The system includes four main blocks - Virtual information system (VIS), Personality Determining System (PDS), Learner Advisory System (LADS) and Learning Environment (LE).

1. Virtual information system provides cooperation between industry, academic and individual learner and gives feedback with information from other main system blocks.

2. Personality Determining System will profile users, assessing their personality based on socionic's theory, Neil Fleming's pedagogic theory, educational psychology and artificial intelligence in order to provide adaptive learning contents for improving performance in learning

3. Learner Advisory System (LADS) system managing learning path for each learner through the course content using different course units, access from different devices and evaluation feedback.

4. Learning Environment will provide a modeling of knowledge domains according to 5 levels of information organization: learning objectives, concepts, learning strategies, content format and ICT supports.

\subsection{Virtual Information System}

The main idea of a virtual information system (VIS) is to provide complete utilization of information and communication technologies (ICT) for cooperation between industry, academic and individual or work-based learner as a useful development model.

Since experts are continuously improving the knowledge database, we assume that the client/server architecture ensures up-to-date information on adults' devices. The fundamental model of a system contains a cascade of three main components that workers and experts can interact with each other.

For describing the model we can use the same approach for individual learner as for worker therefore we can use updated Gravan's model [27]. Human capital accumulation: the role of human resource development) for describing virtual information system VIS. Given the distant nature of learning we must assume that it is necessary that experts can collaborate distantly as well. The use of technology is extremely necessary for the discussion and interaction between the specialists all over the world [28]. 
Presentation layer - A great diversity can be expected among the users of this system as they are going to use a wide variety of devices, so we have to take ICT (e.g. tablets, phones) into account Therefore, we have to develop a system supporting user access through different types of devices. This can be achieved by responsive templates.

Security layer - Every instance of the system is going to contain lots of data that can be potential trade secret. The IS will provide security conditions for protecting sensitive information. There will be at least two roles (actor types) accessing the system, that is experts and workers.

Database - The presentation and security layers will be the same in every instance of the system. Databases will share some similarities but the database is going to be an individual part of the system connected to the controller.

\subsection{Personality Determining System}

Personality determining system (PDS) will profile users, assessing their personality based on socionic theory, Neil Fleming's pedagogic theory, educational psychology and artificial intelligence in order to provide adaptive learning contents for improving performance in learning. This goal will be achieved by integrating multimodal sensing technologies, processing data for understanding users' emotion/attention and, finally, personality, according to the socionic's theory, which is based on Myers-Briggs learning style model and Neil Fleming's pedagogic theory. System will include automatic personality assessment, ontology analyses and artificial intelligence in education.

\subsection{Learner Advisory System}

Learner advisory system (LADS) is an adaptive, intelligent selfdeveloping system managing learning path for each learner through the course content using different course units, access from different devices and evaluation feedback. In this part inherently multidisciplinary research experimentations will be developed on smart learning environments providing students with adaptive and personalized learning and assessment. Also simulation and modeling will be used as a method for researching personalized learning path.

Learner advisory system includes possibility to manage learner personality types and learning strategies in case that learner can use different access devices. System offers two possibilities for user - to choose his own free learning path or follow to recommended learning path. System analyses feedback from learning environment evaluation system in both cases and develops recommended learning path for next user.

Learning Environment will provide a modeling of knowledge domains according to 5 levels of information organization: learning objectives, concepts, learning strategies, content format and ICT supports. A course's learning objectives will be associated with the concepts of the knowledge domain to be taught. Concepts will be taught by an available set of learning strategies that will be delivered to each user according to his/her MBTI personality type. Those learning strategies will be based on the learning theories of behaviorism, cognitivism (particularly constructivism and cultural constructivism) and socio-cultural learning approaches. They will be based also on the Learning Design approach [29] according to which a Unit of Learning consists of roles, activities and supports. Each learning activity implements a learning strategy and consists of several tasks. During each task, learners will be supplied with resources (Content format level) according to their VARK learning style but also they will create resources as task products (e.g. written assignments), according to the same model. ICT supports also will be available for each learning strategy, according to learners' VARK style and according to their MBTI personality type.

The teaching/learning strategies are aligned with the learning preferences of particular types of learners. More specifically, the SLE will promote personalization by being able: a) to deliver to the learners preferable learning designs during a course (Figure 2) to deliver to the learners preferable formats of the learning resources. The first capability will be achieved by recognizing someone's learning preferences according to the Myers-Briggs Inventory for personality types [30,31]. The second capability will be achieved by recognizing the learners' preferences for elaborating information according to the sensory modalities which have been proposed by the VARK model.

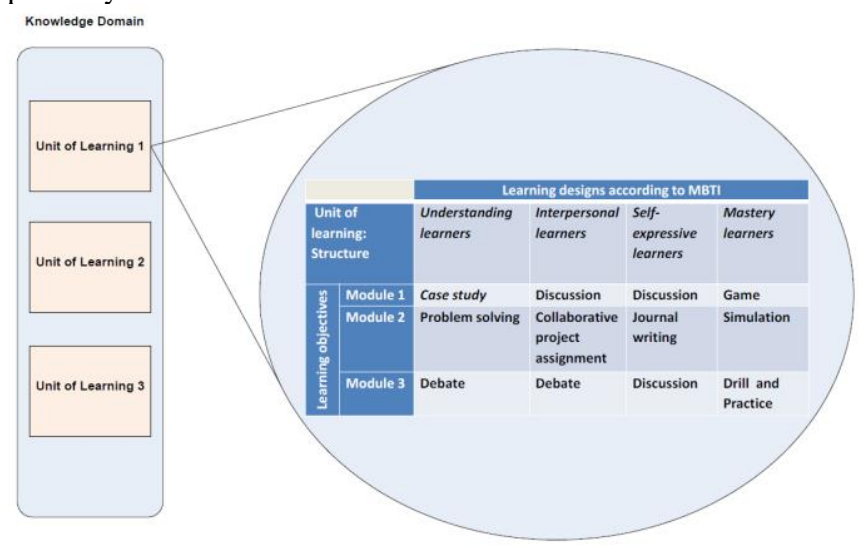

Fig. 2: An example of a course's structure based on the aggregation of Units of Learning.

\section{Conclusion}

Focusing to nowdays pedagocial paradigms teaching and learning changes direction from "teacher to learner" to "learner to teacher". It means that student takes place in the system more actively and affect to the teaching methods and content. From the other side the labour market defines knowledge, competences and skills necessary for each working place. Education system challenge is to develop and coordinate all aspect together.

In the modern day, it is not possible to maintain sustainable competition in professional environment without improving practical skills and knowledge, which leads to increased popularity of further education. Most adults enjoy to get involved in self-led acquisition of new skills and knowledge, provided there is an adequate offer and their motivation is stimulated.

All forms of education are equally important and complement each other thus enriching culture of education, general experience of the learning individuals and broadening the learning environment of the individuals and the general public.

Technological information system is necessary for providing communication between all parts, delivering content and developing education system in common for delivering right information for right student in fast growing information and big data society. It is crucial to continuously monitor the ever changing circumstances of market and apply accessible technological solutions accordingly so as to promote sustainable cooperation between educational institutions and enterprises, attracting potential interns and working individuals.

The development of methods and available technologies increasingly affect development of sustainable society and determines tendencies in education thus changing the nature of adult further education.

\section{Acknowledgement}

Technology Enhanced Learning E-ecosystem with Stochastic Interdependences - TELECI. No.1.1.1.1/16/A/154 


\section{References}

[1] Baltic Institute of Social Sciences. (2006), Mūžizglītības pieejamība un iespējas izglītoties. Internet: http://www.biss.soc.lv/downloads/resources/muzizglitiba/muzizgl_1 atv.pdf, rev. 2014.

[2] Žogla, I. (2002), Didaktikas teorētiskie pamati, Rīga: RaKa, 275 p., ISBN10: 9984153754.

[3] LR Saeima. (2014) Izglītības attīstības pamatnostādnes 2014. - 2020. gadam. Riga. Internet: http://m.likumi.lv/doc.php?id=266406.

[4] Žogla, I. (2001), Pedagoǵiskā paradigma un didaktiskais modelis

[5] Kolb D. A. (1984), Experiental learning: experience as the source of learning and development. Englewood Cliffs, New Jersey: Prentice Hall.

[6] Kolb, D.A. (1981), Learning styles and disciplinary differences In A.W. Chickering (Ed).The modern American college: Responding to the new realities of diverse students and a changing society San Francisco, CA: Jossey Bass, pp.232-255.

[7] Kolb D. A. (2000), Facilitator`s guide to learning. Boston: Hay/MsBer.

[8] LVS ISO 5127:2005. Informācija un dokumentācija. Vārdnīca, Informācijas zinātnes termini.

[9] Shatil E. (2013), Does combined cognitive training and physical activity training enhance cognitive abilities more than either alone? A four-condition randomized controlled trial among healthy older adults. Front. Aging Neurosci. 5:8. doi: 10.3389/fnagi.2013.00008.

[10] Shatil E., Mikulecká J.a, Bellotti F., Burěs V.(2014), "Novel Television-Based Cognitive Training Improves Working Memory and Executive Function”. PLoS ONE July 03, 2014, 10.1371/journal.pone.0101472.

[11] Gard T, Hölzel BK, Lazar SW. (2014), The potential effects of meditation on age-related cognitive decline: a systematic review. Ann N Y Acad Sci. 2014 Jan, 1307:89-103. doi: 10.1111/nyas.12348. 2.

[12] Voss MW et al. (2010), Plasticity of brain networks in a randomized intervention trial of exercise training in older adults. Front Aging Neurosci. 2010 Aug 26,2. pii: 32. doi: 10.3389/fnagi.2010.00032

[13] Verghese J, Mahoney J, Ambrose AF, Wang C, Holtzer R. .(2010) Effect of cognitive remediation on gait in sedentary seniors - J Gerontol A Biol Sci Med Sci. 2010 Dec,65(12):1338-43.

[14] Shatil E, Korczyn AD, Peretzc C, et al. (2008), Improving cognitive performance in elderly subjects using computerized cognitive training - Alzheimer's \& Dementia: The Journal of the Alzheimer's Association 2008; 4(4):T492.

[15] Korczyn AD, Peretz C, Aharonson V, et al.(2007), "Computer based cognitive training with CogniFit improved cognitive performance above the effect of classic computer games: prospective, randomized, double blind intervention study in the elderly". Alzheimer's \& Dementia: The Journal of the Alzheimer's Association 2007; 3(3):S171

[16] Dreambox learning. (2017), Individualized Learning, http://www.dreambox.com/individualized-learning/ 2017.

[17] Medium. The Office of Educational Technology (OET), 2017, https://medium.com/personalizing-the-learning-experienceinsights/what-is-personalized-learning-bc874799b6f.

[18] Аугустинавичюте А.(1998), Соционика. Введение - Москва: АКТ Астраль, 448 с

[19] Briggs Myers I., Briggs Myers P. (1995), Gifts Differing: Understanding Personality Type. Mountain View, CA: Davies-Black Publishing.

[20] Briggs Myers I.; McCaulley, Mary H.; Quenk, Naomi L.(2009), Hammer, Allen L.; Mitchell, Wayne D. MBTI Step III Manual: Exploring Personality Development Using the Myers-Briggs Type Indicator Instrument, Consulting Psychologists Press.

[21] Гуленко В. (1999), Структурно - функциональная соционика Киев: Транспорт України, 187 с.

[22] Rodgers C. (2002), Defining Reflection: Another Look at John Dewey and Reflective Thinking. Teachers College Record , 2002, v104 n4, 842-848.

[23] Rogers J. (1997), Sixteen personality types at work in organizations - London: Management Futures. 32 p.

[24] Grant P., Basye D. A.(2014). Personalized Learning: Guide for Engaging Students with Technology, International Society for Technology in Education.

[25] Jasper M. (2003), Beginning Reflective Practice,Cheltenham, NelsonThornes.

[26] King T. (2002), Development of student skills in reflective writing Proceedings of the $4^{\mathrm{Th}}$ World Conference of the International Consortium for Educational Development in Higher Education, 3-6 July.
[27] Gravan, T., Morley M.(2013), Gunnigle P., Eammon C., Human capital accumulation: the role of human resource development.

[28] Seufert, S. (2000), Work Based Learning and Knowledge Management: An Integrated Concept of Organizational Learning. ECIS 2000 Proceedings, p 148

[29] Koper, R. \& Tattersall, C. (2005), "Preface to Learning Design: A Handbook on Modelling and Delivering Networked Education and Training." Journal of Interactive Media in Education, 2005(18).

[30] Silver, Harvey F.; Strong, Richard W.; Perini, Matthew J. (2007), The Strategic Teacher: Selecting the Right Research-Based Strategy for Every Lesson, Association for Supervision and Curriculum Development.

[31] Silver F, Strong R, Perini M. (2000), So Each May Learn: Integrating Learning Styles and Multiple Intelligences. ASCD. 